\title{
An atypical assessment of Ebstein's anomaly in an 86-year-old man
}

\section{Un caso atipico di anomalia di Ebstein in un uomo di 86 anni}

\author{
Antonello D'Andrea, Giancarlo Scognamiglio, Franco Giordano1, Sergio Cuomo, \\ Maria Giovanna Russo, Genny Rinaldi1, Raffaele Calabrò
}

\begin{abstract}
An atypical assessment of Ebstein's anomaly in an 86-year-old man. A. D'Andrea, G. Scognamiglio, F. Giordano, S. Cuomo, M.G. Russo, G. Rinaldi, R. Calabrò.

We present the echocardiographic analysis of an 86year-old man affected by Ebstein's anomaly. In the natural history of this congenital disease only $5 \%$ of patients survive
\end{abstract}

beyond the fifth decade. The patient presented severe right atrial dilatation and right heart failure, and he was referred to our institution for supraventricular tachycardia.

Keywords: Ebstein's anomaly, echocardiography, elderly.

Monaldi Arch Chest Dis 2011; 76: 104-105.

Chair of Cardiology - Second University of Naples.

1 Cardiology - Civil Hospital of Agropoli - Salerno, Italy.

Corresponding author: Antonello D'Andrea, MD; Via M. Schipa 44; I-80122 - Naples - Italy; Tel: ++390817618525; Fax: ++390817145205; E-mail address: antonellodandrea@libero.it

\section{Case report}

An 86-year-old man was admitted to our hospital because of fatigue, dyspnea and palpitations. The patient had experienced feelings of fainting since several days. Cardiac examination revealed a heart murmur. He had a diagnosis of Ebstein's anomaly done when he was 40 years old and was not initially referred for surgery. Actually, he presented with signs and symptoms of right heart failure (pleural effusion, hepatomegaly, low extremities edemas), reduced exercise tolerance and effort dyspnea (NYHA class III). He showed recent worsening of his clinical status with frequent episodes of palpitations. The electrocardiogram showed atrial fibrillation. During the analysis in Emergency room at the same time that he complained of feelings of fainting, the electrocardiogram showed non-sustained ventricular tachycardia. The echocardiogram detected apical displacement of the septal tricuspid leaflet, severe tricuspid valve regurgitation and severe dilatation of both right ventricle and of right atrium (Figure 1). Because of advanced age and cardiac dysfunction, corrective or palliative surgical procedures were excluded and the patient underwent only intravenous medical therapy.

\section{Discussion}

Ebstein's anomaly is a rare congenital heart disorder occurring in 1 per 200.000 live births and accounting for $<1 \%$ of al congenital heart diseases [1]. Ebstein anomaly is characterized by apical displacement of the septal and posterior tricuspid valve leaflets, leading to atrialization of the right ventricle with a variable degree of malformation and displacement of the anterior leaflet. The leaflet anomalies lead to tricuspid regurgitation [2-3]. The severity of regurgitation depends on the extent of leaflet displacement, ranging from mild regurgitation with minimally displaced tricuspid leaflets to severe regurgitation with extreme displacement. The atrialized portion of the right ventricle, although anatomically part of the right atrium, contracts and relaxes with the right ventricle. This discordant contraction leads to stagnation of blood in the right atrium. During ventricular systole, the atrialized part of the right ventricle contracts with the rest of the right ventricle, which causes a backward flow of blood into the right atrium, accentuating the effects of tricuspid regurgitation [4-5].

The clinical manifestations of this anomaly are quite variable, depending upon the spectrum of pathology and the presence of associated malformations. It is well documented that a considerable proportion of these patients are able to survive into adult life. However, the patient who survives into the fifth decade without a sign of heart failure is extremely rare $(<5 \%)$ [6-10]. We speculate that our patient had not developed right ventricular failure until his 80 's because he had a milder form of Ebstein's anomaly and did not have any other congenital heart disease. 


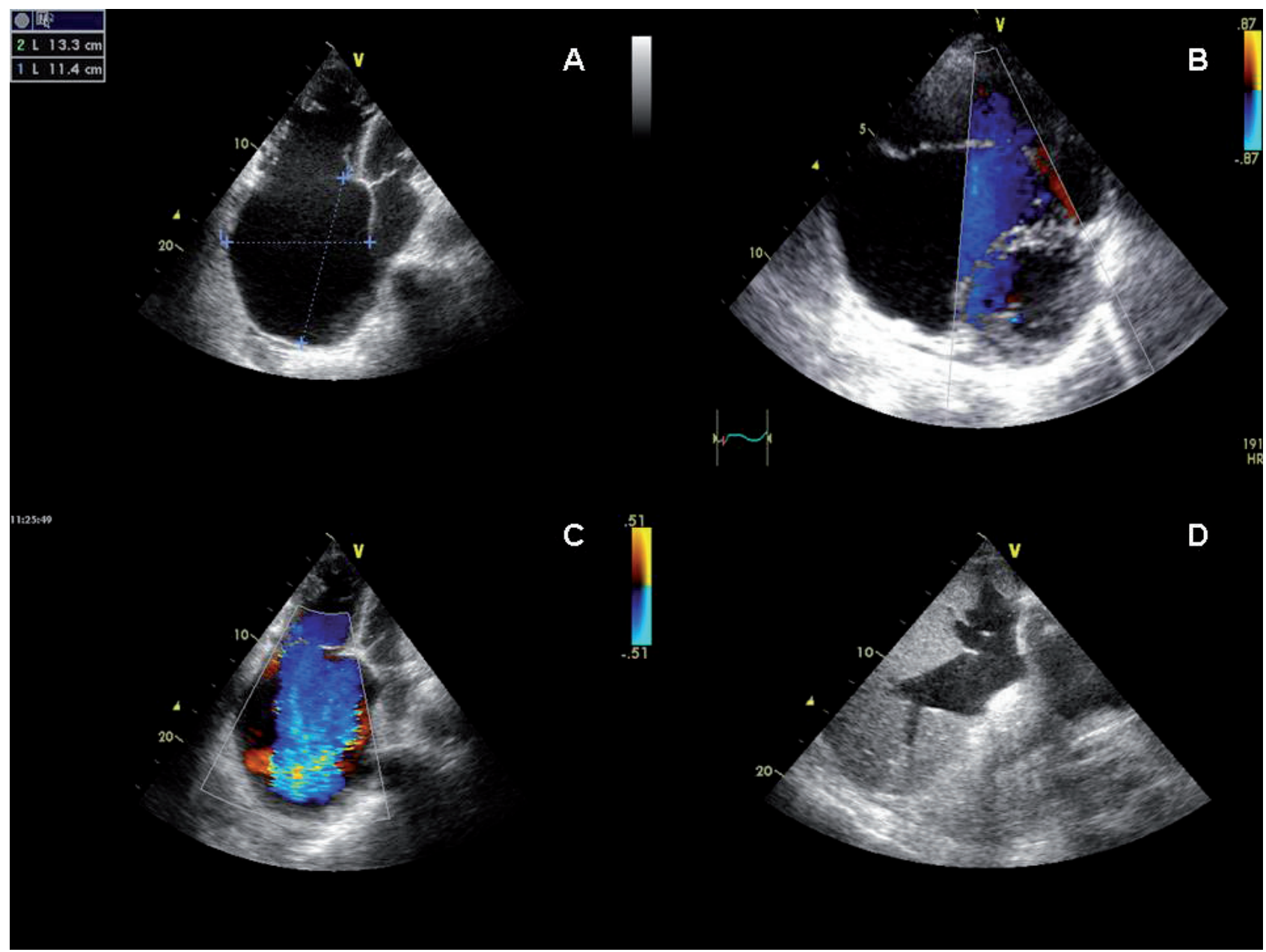

Figure 1. - Transthoracic echocardiography view showing: (a) in parasternal short-axis view downward displacement of the septal leaflet of the tricuspid valve in relation to the anterior mitral valve leaflet; b) in apical four-chamber view giant right atrium (RA), atrialized portion of right ventricle, and true right ventricle (RV); (c) severe tricuspid valve regurgitation due to the anomalous valvular arrangement; (d) severe inferior vena cava dilatation (4 cm).

\section{Riassunto}

Questo caso clinico descrive le caratteristiche ecocardiografiche di un paziente di 86 anni affetto da anomalia di Ebstein. Solo il 5\% dei soggetti affetti da tale cardiopatia congenita supera solitamente la quinta decade di vita. Il nostro paziente presentava una severa dilatazione atriale destra e segni di scompenso cardiaco destro, e giungeva alla nostra osservazione per insorgenza di fibrillazione atriale parossistica.

Aknowledgments: The authors are grateful to all the nurses of the Intensity Care Unit of the department of Cardiology of the Civil Hospital of Agropoli for the optimal technical assistance in the management of our patients.

\section{References}

1. Muñoz-Castellanos L, Espinola-Zavaleta N, Kuri-Nivón M, Keirns C. Ebstein's Anomaly: anatomo-echocardiographic correlation. Cardiovasc Ultrasound 2007; 5: 43.
2. Khositseth A, Khowsathit P. Factors affecting mortality in Ebstein's anomaly of the tricuspid valve. J Med Assoc Thai 1999; 82 Suppl 1: S10-5.

3. Attie F, Casanova JM, Zabal C, Buendía A, Miranda I, Rijlaarsdam M. Ebstein's anomaly. Clinical profile in 174 patients. Arch Inst Cardiol Mex 1999; 69(1): 17-25.

4. Celermajer DS, Bull C, Till JA, Cullen S, Vassillikos VP, Sullivan ID. Ebstein's anomaly: presentation and outcome from fetus to adult. J Am Coll Cardiol 1994; 23(1): 170-6.

5. Hong YM, Moller JH. Ebstein's anomaly: a long-term study of survival. Am Heart J 1993; 125(5 Pt 1): 1419-24.

6. Attie F, Rosas M, Rijlaarsdam M, et al. The adult patient with Ebstein anomaly. Outcome in 72 unoperated patients. Medicine (Baltimore) 2000; 79(1): 27-36.

7. Augustin N, Schreiber C, Lunge R. Valve preserving treatment of Ebstein's anomaly: perioperative and followup results. Thorac Cardiovasc Surg 2000; 48(5): 316.

8. Chauvaud S. Ebstein's malformation. surgical treatment and results. Thorac Cardiovasc Surg 2000; 48(4): 220-3.

9. MacLellan-Tobert SG, Driscoll DJ, Mottram CD, Mahoney DW, Wollan PC, Danielson GK. Exercise tolerance in patients with Ebstein's anomaly. I Am Coll Cardiol 1997; 29(7): 1615-22.

10. Perloff JK. Ebstein's anomaly of the tricuspid valve. In: Perloff JK, ed. The Clinical Recognition of Congenital Heart Disease. $3^{\text {rd }}$ ed. Philadelphia, Pa: WB Saunders Company; 1991: 235-251. 